\title{
Avaliação da competência social em crianças em situação de risco ${ }^{1}$
}

\author{
Alessandra Marques Cecconello ${ }^{2,3}$ \\ Silvia Helena Koller
}

\begin{abstract}
Resumo
Este artigo descreve a adaptação do Teste das Histórias Incompletas (THI) para avaliação da competência social com crianças brasileiras que vivem em situação de risco. O THI consiste em quinze histórias incompletas que avaliam competência social por meio de três subescalas, que são confiança, auto-eficácia e iniciativa. Participaram deste estudo 100 crianças escolares entre seis e nove anos. As análises mostraram diferença significativa entre os sexos e entre as idades, nas quais as meninas e as crianças mais velhas obtiveram melhores resultados do que as demais, sendo mais competentes socialmente. Este estudo permite considerar que características como confiança, auto-eficácia e iniciativa podem ser analisadas como atributos de competência social, as quais podem servir para embasar o planejamento de programas de intervenção que visem ao desenvolvimento da competência social. Neste sentido, o THI consiste em um importante instrumento que pode ser utilizado como recurso de avaliação para subsidiar tais programas.

Palavras-Chave: Competência social; Risco; Instrumento; Intervenção.
\end{abstract}

\section{Assessment of social competence in children under risk situation}

\begin{abstract}
This paper describes the Incomplete Stories Test (IST) adaptation to assessment of social competence in Brazilian children living under risk situation. The IST consists of fifteen incomplete stories that assess social competence through three subscales, trust, self-efficacy and active coping. A hundred school children, ranged from six to nine years old, participated in this study. The analysis demonstrated sex and age-groups significant difference, in which the girls and the oldest group achieved better results than the others, being more socially competent. This study permits to consider that characteristics of trust, self-efficacy, and active coping could be analyzed as social competence attributes, which can serve to subsidiate the planning of intervention programs that aim to develop social competence. So, the IST consists in an important measure, that can be useful as an assessment resource to these programs.
\end{abstract}

Keywords: Social competence; Risk; Measure; Intervention.

\section{Introdução}

A temática do desenvolvimento humano em situações de risco vem sendo discutida por vários autores desde a década de 70 (Coddington, 1972; Garmezy \& Masten, 1994; Garmezy, Masten \& Tellegen, 1984; Masten \& Garmezy, 1985; Rutter, 1985, 1987, 1993, 1996; Werner \& Smith, 1982, 1992; Zigler \& Trickett, 1978). A principal preocupação desses pesquisadores reside em identificar fatores que auxiliam as pessoas a manterem um desenvolvimento saudável na presença das adversidades. Nesse sentido, o enfoque dessas pesquisas consiste em identificar fatores de risco e proteção que contribuem para a adaptação, com o objetivo de subsidiar programas de intervenção e políticas públicas em saúde mental e resiliência.

Para Masten (2001), resiliência refere-se ao fenômeno caracterizado por resultados positivos na presença de sérias ameaças à adaptação ou ao desenvolvimento da pessoa. A adaptação tem um papel central no desenvolvimento da resiliência, no entanto, ainda gera controvérsias entre os pesquisadores do assunto. Alguns estudiosos definem adaptação baseados nas tarefas evolutivas esperadas para o ser humano ao

\footnotetext{
${ }^{1}$ Este estudo faz parte da Dissertação de Mestrado em Psicologia do Desenvolvimento da primeira autora, orientada pela segunda autora.

2 Apoio CNPq.

3 As autoras agradecem a participação dos bolsistas de Iniciação Científica que participaram desta pesquisa.

Endereço para correspondência:
}

CEP-RUA/UFRGS - Instituto de Psicologia, Rua Ramiro Barcelos, 2.600/104 - Porto Alegre-RS - 90035-003. Fone: (051)

3316-5150. Fax: (51) 3333-9819.

E-mail:marquesa@terra.com.br 
longo de seu ciclo vital e nas expectativas culturais, que variam de acordo com o contexto histórico-políticosocial-econômico no qual está inserido. Nessa perspectiva, a competência social consiste em uma variável por meio da qual se podem mensurar níveis de adaptação (Elder, 1998; Masten \& Coatsworth, 1995; Mondell \& Tyler, 1981; Waters \& Sroufe, 1983). Outros pesquisadores, principalmente no campo da prevenção de psicopatologia e abuso de substâncias, focalizam a adaptação na ausência de transtornos de personalidade, de comportamento, ou no baixo nível dos sintomas (Conrad \& Hammen, 1993).

A competência social tem sido, freqüentemente, utilizada por alguns autores como uma variável para avaliar níveis de ajustamento e adaptação (Garmezy, Masten \& Tellegen, 1984; Kliewer, 1991; Luthar \& Zigler, 1991; Mondell \& Tyler, 1981; Waters \& Sroufe, 1983; Zigler \& Trickett, 1978). Esses autores entendem a competência social como a habilidade da pessoa para perceber as demandas do ambiente e o esforço com o objetivo de adequar seu próprio comportamento à situação. Além disso, destacam a capacidade para apresentar características importantes para o desenvolvimento, como auto-estima e auto-eficácia (Kliewer, 1991; Waters \& Sroufe, 1983; Zigler \& Trickett, 1978).

Tyler (1984) define competência social baseado em aspectos individuais e sociais do funcionamento humano. Descreve a competência social como a maneira como a pessoa interage com os eventos de vida, tanto num sentido de resolução de problemas, como num sentido de auto-realização. Destaca três características importantes para ela, quais sejam, confiança otimista nas pessoas e no mundo; auto-eficácia, auto-avaliação positiva e controle dos eventos de vida pessoal; e, iniciativa, mediante o estabelecimento de objetivos realistas e esforços tendo em vista alcançá-los. Além disso, Tyler avalia a capacidade para desfrutar do êxito, sofrer com os fracassos e construir com base em ambos. Com base na análise dessas características é possível fazer inferências sobre a competência social da pessoa, pois supõe-se que por trás delas existem boas estratégias de enfrentamento para a resolução de problemas (Tyler, 1984).

Nesse sentido, para Tyler (1984) uma pessoa competente é capaz de acreditar em suas potencialidades e demonstrar sentimentos positivos com relação a si mesmo. Além disso, é capaz de estabelecer metas e traçar estratégias para conseguir bons resultados, mesmo tendo fracassado em experiências anteriores. Em contraste, as pessoas menos competentes socialmente são menos auto-eficazes, consideram que possuem menos controle sobre suas vidas, menos confiança e são, ainda, menos ativas com relação ao planejamento de suas vidas (Tyler, 1984).

Tyler (1984) ressalta, entretanto, que a compe- tência é um fenômeno psicossocial, ou seja, os padrões característicos de competência variam de acordo com o contexto socioeconômico-cultural no qual a pessoa está inserida, podendo ser influenciados por ele. Os níveis de auto-eficácia são consistentemente mais baixos em grupos com oportunidades restritas para a autonomia. Da mesma forma, os padrões de confiança são mais baixos entre as pessoas discriminadas socialmente, como, por exemplo, por sua raça, gênero ou nível socioeconômico. Nesse sentido, destaca-se a importância da avaliação da competência social em crianças para a prevenção de problemas adaptativos.

A avaliação da competência social como um construto multidimensional, conforme proposta por Tyler (1984), tem sido um desafio para os pesquisadores, especialmente quando o objetivo é avaliar a competência de crianças escolares. Mondell e Tyler (1981) elaboraram um instrumento para avaliar a competência social em crianças - o Teste das Histórias Incompletas (THI). O THI é composto por quinze histórias incompletas que avaliam a competência social investigando características pessoais por meio das subescalas de confiança, auto-eficácia e iniciativa. A subescala de confiança avalia a capacidade da pessoa para estabelecer relações de confiança com pessoas significativas. A subescala de auto-eficácia avalia a capacidade da pessoa para demonstrar sentimentos de controle pessoal e de responsabilidade sobre os eventos de suas vidas. A subescala de iniciativa avalia a capacidade da pessoa para estabelecer estratégias a fim de alcançar seus objetivos, empenhando-se em solucionar os problemas que lhe são propostos. Baseados na suposição de que grupos de crianças com funcionamento competente, mediano e pobre poderiam ser diferenciados por seus atributos de competência psicossocial, Mondell e Tyler pressupu-seram que grupos mais competentes demonstrariam níveis mais altos de confiança, autoeficácia e iniciativa do que os demais.

Examinaram uma amostra de 215 crianças, entre sete e doze anos, de nível socioeconômico médio, divididas em quatro grupos. Dois grupos foram compostos por crianças com suposto "funcionamento adequado" (Mondell \& Tyler, 1981, p. 148) e dois, compostos por crianças em atendimento clínico. Nos quatro grupos, as crianças foram classificadas a priori por juízes de acordo com o critério de ajustamento social e adaptação, com o objetivo de incluir crianças com vários níveis de ajustamento. $\mathrm{O}$ primeiro grupo (G1) foi composto por 81 alunos de uma escola fundamental, oriundos de uma comunidade do subúrbio de Massachusetts. Nesse grupo, foi solicitado aos professores que classificassem seus alunos baseados no seu desempenho acadêmico e no relacionamento com pares e autoridades. Os professores identificaram 
dois subgrupos de crianças: um extremamente competente e um mediano.

O segundo grupo (G2) foi composto por 51 crianças que estavam participando de um acampamento de verão (YMCA), oriundas de outra comunidade também do subúrbio de Massachusetts. Esse grupo não pôde ser avaliado com relação ao critério de ajustamento social em virtude dos limites impostos pelo ambiente. Contudo, em razão da diferença de adaptação apresentada com relação à amostra clínica, ele foi classificado como ajustamento mediano.

O terceiro grupo (G3) foi composto por 43 crianças que participavam de um programa terapêutico por causa de problemas emocionais e de comportamento. O quarto grupo (G4) foi composto por 40 crianças em atendimento clínico em um hospital em virtude de problemas de aprendizagem e de comportamento. Esses dois grupos de crianças foram classificados como ajustamento pobre, graças aos sintomas de psicopatologia apresentados.

Em todos os grupos foi aplicado, individualmente, o THI. No terceiro grupo (G3), também, foi aplicada a escala Nowicki-Strickland I-E para avaliar o locus de controle, visto que essa variável encontra-se relacionada com a competência social. Essa escala avalia o grau em que os resultados do comportamento da pessoa são percebidos como decorrentes de seu próprio esforço, em oposição a causas externas, como sorte, destino ou ajuda de outras pessoas. Esse instrumento era aplicado rotineiramente nas crianças desse programa terapêutico, por isso, foi utilizado, também, por Mondell e Tyler. No quarto grupo (G4) foi aplicada a escala Wechsler para avaliação da inteligência, por causa da presença de dificuldades de aprendizagem nas crianças desse grupo.

Conforme esperado pelos autores, houve diferença significativa entre os quatro grupos de crianças nas subescalas de auto-eficácia, iniciativa e competência total, sendo as médias das crianças da amostra nãoclínica (G1 e G2) mais altas do que as da amostra clínica (G3 e G4). No terceiro grupo (G3), houve correlação entre as subescalas de confiança, auto-eficácia e escala total de competência social com o locus de controle. As crianças mais competentes socialmente apresentavam locus de controle interno, confirmando a influência desta variável para a competência social. No quarto grupo (G4), houve correlação entre o nível de inteligência e o escore total de competência social, sendo que as subescalas do THI não se correlacionaram com a inteligência. Apesar dessa correlação, Mondell e Tyler (1981) ressaltam que inteligência e competência social são construtos independentes.

Foi investigada diferença entre os sexos somente na amostra não-clínica (G1 e G2), na qual a representatividade de ambos os sexos estava emparelhada. Os resultados não demonstraram diferença significativa entre os sexos nessa amostra, apesar de que as meninas pontuaram consistentemente mais alto do que os meninos. Diferença entre grupos etários $(7 / 8$, $9 / 10,11 / 12)$, entretanto, foi encontrada nessa amostra. Nas subescalas de confiança, iniciativa e competência total as crianças de nove e dez anos tiveram um desempenho significativamente melhor do que as de sete e oito anos. As de onze e doze anos não demonstraram diferença significativa com as demais.

A análise do coeficiente de alpha de Cronbach do THI foi de 0,98. Os resultados das análises desse instrumento levaram Mondell e Tyler (1981) a confirmar sua hipótese de que características como confiança, auto-eficácia e iniciativa variam sistematicamente entre crianças identificadas como mais competentes e menos competentes, sendo que as mais competentes e melhor ajustadas pontuam mais alto nas subescalas e na escala total do THI. As crianças menos competentes tendem a ser distinguidas das demais pela sua baixa iniciativa, ao passo que as mais competentes tendem a ser distinguidas pelo seu alto nível de auto-eficácia, ou seja, pelo sentimento de controle e responsabilidade pessoal sobre suas vidas. Esses resultados têm implicações relevantes para a elaboração de programas de intervenção com crianças, nos quais é necessário focalizar o desenvolvimento de habilidades e características importantes, como a confiança e a auto-eficácia, para que elas se tornem mais envolvidas na resolução de seus problemas pessoais.

O THI demonstrou ser um instrumento eficaz para avaliar a competência social (Mondell \& Tyler, 1981). Além de lúdico, o conteúdo das histórias foi facilmente compreendido pelas crianças, pois envolvia situações cotidianas. Nesse sentido, demonstrou ser um instrumento versátil, de fácil administração e avaliação. Baseado nessas qualidades do instrumento e na sua aplicação prática em programas de intervenção, este estudo teve como objetivo avaliar a competência social em crianças que vivem em situação de risco, adaptando o THI para a utilização com crianças brasileiras.

\section{Método}

\section{Participantes}

Participaram deste estudo 100 crianças (50 meninos e 50 meninas), com idades entre seis e nove anos $(\underline{m}=7,81 ; \underline{\mathrm{d}}=0,86)$, estudantes de primeira a terceira séries de duas escolas públicas de Porto Alegre. As crianças foram indicadas pelas escolas para participar da pesquisa de acordo com o critério de situação de risco, determinado pelo baixo nível socioeconômico (renda familiar abaixo de três salários mínimos) e local 
de residência (vilas com alto índice de violência e tráfico de drogas).

\section{Instrumento}

O Teste das Histórias Incompletas (THI), proposto originalmente por Mondell e Tyler (1981), foi inicialmente traduzido para a utilização com crianças brasileiras em uma versão preliminar por Marques, e colaboradores (1997). O instrumento e o manual de avaliação foram traduzidos do Inglês para o Português e alguns termos originais foram substituídos por outros, como, por exemplo, "menina popular na escola" por "menina muito conhecida na escola", termos mais adequados ao contexto cultural brasileiro e à realidade dos participantes da pesquisa.

Após um projeto piloto, o THI foi submetido a uma adaptação, com a inclusão de ilustrações, elaboradas por Giovani Andreoli, que tinham como objetivo facilitar a verbalização das crianças (Cecconello, 1999). Cada história recebeu uma ilustração, que era apresentada à criança na medida em que o entrevistador lia as histórias, estimulando sua participação. As ilustrações foram elaboradas com base nos elementos descritos nas histórias. Nesse sentido, tomou-se cuidado na elaboração do desenho para que suas características parecessem "neutras" às crianças, não as inclinando a atribuir determinados finais. As ilustrações foram realizadas no Brasil e enviadas, posteriormente, para os autores do instrumento original, Mondell e Tyler, para que as avaliassem. Os autores aprovaram a inclusão desse recurso gráfico.

O THI consiste em 15 histórias incompletas que envolvem interações cotidianas entre crianças e seus pais, irmãos, professores e colegas, que são lidas para a criança e lhes é solicitado que atribuam um final e/ou uma explicação lógica ou justificativa para os acontecimentos relatados. Essas histórias são divididas nas subescalas confiança, auto-eficácia e iniciativa.

Uma das histórias da Subescala de Confiança é a seguinte: "Marcos ficou furioso, porque seu novo carro de brinquedo quebrou enquanto ele brincava: 'Por que meus brinquedos preferidos sempre quebram?' Nesse momento, Sérgio, seu irmão mais velho, entrou e perguntou qual era o problema. Então, Marcos explicou como o seu carro tinha quebrado. Sérgio disse: 'Não se aborreça. Eu posso consertar seu carrinho amanhã'. 'Eu espero que tu consigas', pensou Marcos. No dia seguinte, depois da escola, Marcos viu Sérgio com uma faca e o carrinho em sua mão. $O$ que você acha que aconteceu depois?"

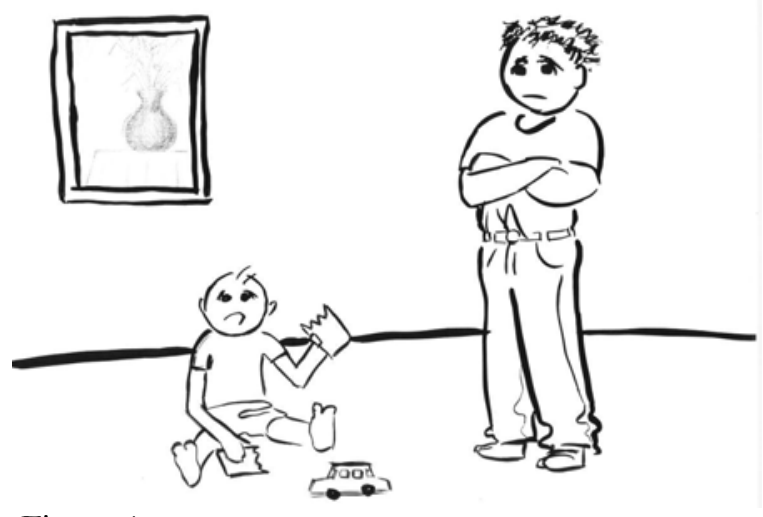

Figura 1.

Uma das histórias da Subescala de Autoeficácia é a seguinte: "Todo mundo a chamava de 'Fernanda Sortuda', porque as coisas boas pareciam sempre acontecer com ela. Todos sabiam que Fernanda era a favorita na aula de Educação Física da escola, onde seu pai era professor. Mas, Fernanda também praticava muita ginástica, mais do que qualquer outra pessoa. Um dia, seu pai organizou uma competição de ginástica na aula. Era uma competição só para alunos da turma. Adivinha quem venceu? Certo, foi Fernanda. Porque você acha que isso aconteceu?"

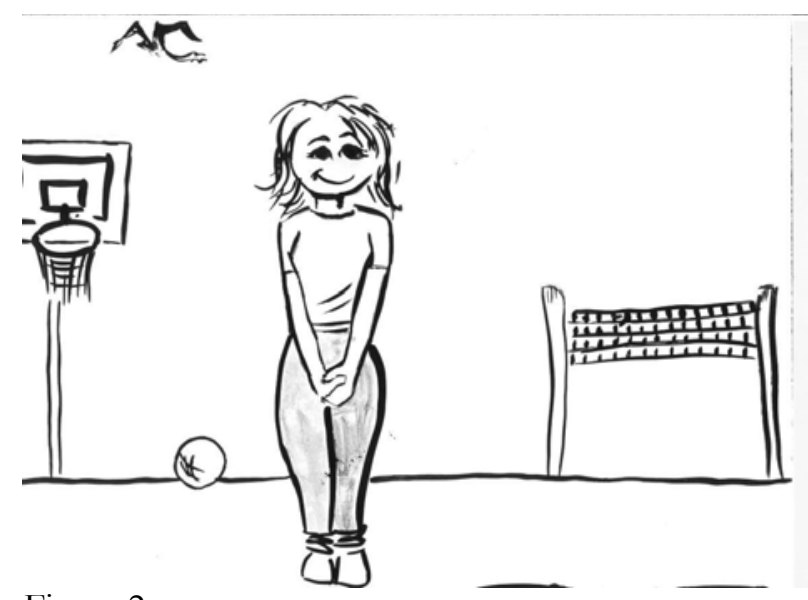

Figura 2.

Uma das histórias da Subescala de Iniciativa é a seguinte: "O irmão mais novo de Mariana, Frederico, vai fazer aniversário daqui a uma semana e Mariana ainda não tem um presente para ele. Ela queria dar um presente surpresa para ele, mas não sabe o que ele gostaria de ganhar ou como fazer para conseguir um presente sem que ele fique sabendo. Mariana pensou: 'Como posso conseguir um presente para o Frederico sem que ele veja'? O que você acha que aconteceu a seguir?" 


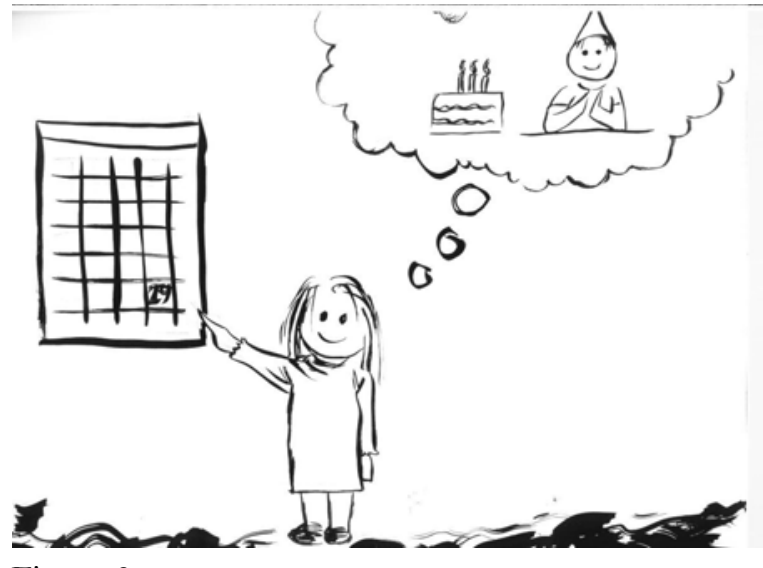

Figura 3.

Com relação à avaliação, em cada subescala, as histórias podem ser pontuadas com dois, um, ou zero pontos, de acordo com o Manual de Pontuação (Mondell \& Tyler, 1981), também adaptado para o uso com essa população por Cecconello (1999). As respostas mais competentes são avaliadas com dois pontos, respostas mistas ou ambíguas recebem um ponto e respostas não competentes recebem zero. As respostas mistas ou ambíguas caracterizam-se por não ser facilmente identificadas como mais competentes ou menos competentes, ou por contemplar ambos os requisitos. Exemplos de respostas desse tipo incluem finais mistos, nos quais a criança apresenta justificativas baseadas em argumentos considerados competentes e não competentes. Em geral, o entrevistador pode recorrer a uma pergunta de apoio com o objetivo de esclarecer as respostas mistas, no entanto, caso a criança continue apresentando uma resposta ambígua, essa recebe apenas um ponto.

$\mathrm{Na}$ subescala de confiança, os finais considerados mais competentes são aqueles com maior grau de otimismo e confiança interpessoal. Finais pessimistas e destrutivos são considerados menos competentes. Para a história dessa subescala, um exemplo de final competente seria baseado no conserto do brinquedo, ou seja, quando a criança afirma que Sérgio consertou o brinquedo de Marcos. Como final pessimista, um exemplo seria a criança afirmar que Sérgio não conseguiu consertar o brinquedo de Marcos ou que o estragou ainda mais. Um exemplo de resposta ambígua seria a criança afirmar que Sérgio consertou o brinquedo de Marcos, mas que o conserto ficou ruim.

$\mathrm{Na}$ subescala de auto-eficácia, os finais mais competentes são aqueles em que os esforços e comportamentos da criança são vistos como responsáveis pelos resultados. Finais menos competentes são aqueles em que a sorte ou forças externas às crianças são vistas como responsáveis pelos resultados. Para a história dessa subescala, um exemplo de final competente seria a criança mencionar que Fernanda conseguiu vencer a competição graças ao seu próprio esforço, ou seja, porque ela praticava muita ginástica. Como final menos competente, um exemplo seria a criança mencionar que Fernanda venceu a competição porque seu pai era o professor. Um exemplo de resposta ambígua seria a criança afirmar que Fernanda venceu a competição porque seu pai era o professor e a incentivava a praticar ginástica em casa.

$\mathrm{Na}$ subescala de iniciativa, os finais nos quais a criança toma, ativamente, alguma decisão e se esforça para resolver o problema proposto são vistos como mais competentes. Finais menos competentes são aqueles em que a criança decide não tomar nenhuma atitude, desiste, ou permite que outra pessoa resolva o problema. Para a história dessa subescala, um exemplo de final competente seria a criança responder que Mariana procura descobrir, através da mãe ou de outros amigos do irmão, o que ele gostaria de ganhar e utiliza suas economias para comprar o presente para o irmão. Como final menos competente, um exemplo seria a criança responder que Mariana pede para que a mãe ou outra pessoa escolha e compre um presente para o seu irmão, sem a sua participação, ou quando a irmã desiste de fazer uma surpresa para Frederico. Um exemplo de resposta ambígua seria a criança afirmar que Mariana descobre o que Frederico gostaria de ganhar e pede para que sua mãe compre o presente para o irmão.

A soma dos escores de cada subescala pode totalizar dez pontos, e a soma do escore de competência total pode totalizar 30 (trinta) pontos.

\section{Procedimentos}

As escolas foram contatadas após uma visita inicial à Secretaria de Educação do Município que teve como objetivo obter o consentimento informado para a realização da pesquisa. Posteriormente, foram realizadas reuniões com a equipe de direção e professores das escolas para explicitar os objetivos do estudo e os procedimentos a serem adotados pela equipe de pesquisadores. O contato com os pais e/ou responsáveis pelas crianças foi realizado durante as reuniões de entrega de boletins, ocasião em que foi solicitado consentimento para que seus filhos participassem da pesquisa.

As respostas atribuídas pelas crianças no THI foram analisadas individualmente por dois avaliadores treinados para essa tarefa. Posteriormente, foram feitas reuniões com o objetivo de comparar os resultados com relação à pontuação e obter consenso. Quando não houve concordância entre os dois avaliadores, um terceiro avaliador, igualmente capacitado, intervinha no processo e participava da discussão até obter consenso. 


\section{Resultados e Discussão}

As respostas atribuídas pelas crianças no THI foram categorizadas de acordo com o Manual de Pontuação e submetidas à análise estatística. Foram calculadas as médias, desvios padrão, intervalos de confiança, diferenças entre os sexos e entre idades para a competência social. A Tabela 1 apresenta a análise das médias, desvios padrão e intervalos de confiança para as subescalas de confiança, auto-eficácia e iniciativa e para escala de competência total do THI.

Tabela 1 - Médias, Desvios Padrão e Intervalos de Confiança para a Competência Social e Subescalas no THI $(\underline{n}=100)$

\begin{tabular}{l|cccc}
\hline & Escore mínimo & Escore máximo & Média & $\underline{\mathrm{dp}}$ \\
\hline Confiança & 0 & 10 & 4,59 & 2,17 \\
Auto-Eficácia & 2 & 10 & 6,72 & 1,88 \\
Iniciativa & 1 & 10 & 5,98 & 1,83 \\
Competência Total & 9 & 27 & 17,29 & 4,06 \\
\hline
\end{tabular}

Uma análise de variância (ANOVA) demonstrou diferença entre os sexos, tendo as meninas obtido melhores resultados do que os meninos (ver Tabela 2). Houve diferença significativa nas subescalas de confiança $(\underline{\mathrm{F}}(1,98)=5,76 ; \quad \mathrm{p}<0,05), \quad$ auto-eficácia $\quad(\underline{\mathrm{F}}(1,98)=4,24 ;$ $\mathrm{p}<0,05)$ e competência total $(\underline{\mathrm{F}}(1,98)=8,65 ; \mathrm{p}<0,05)$, demonstrando que as meninas tendem a ser mais competentes socialmente do que os meninos. $\mathrm{Na}$ subescala de iniciativa essa diferença não foi encontrada.

Tabela 2 - Diferença entre os Sexos para a Competência Social no THI $(\underline{\underline{n}}=100)$

\begin{tabular}{lcccc}
\hline Escalas & Sexo & Média & $\underline{\text { dp }}$ & $\underline{\mathrm{F}}(1,98)$ \\
\hline Confiança & $\mathrm{M}$ & 4,08 & 2,13 & $5,76^{*}$ \\
Auto-Eficácia & $\mathrm{F}$ & 5,10 & 2,12 & \multirow{2}{*}{$4,24^{*}$} \\
& $\mathrm{M}$ & 6,34 & 2,01 & \\
Iniciativa & $\mathrm{F}$ & 7,10 & 1,66 & 2,05 \\
& $\mathrm{M}$ & 5,72 & 1,86 & \multirow{2}{*}{$8,65^{*}$} \\
Competência Total & $\mathrm{F}$ & 6,24 & 1,77 & \\
& $\mathrm{M}$ & 16,14 & 4,00 & 3,81 \\
\hline
\end{tabular}

${ }^{* \mathrm{p}}<0,05$

A análise da subescala de iniciativa aponta, entretanto, para uma diferença significativa com relação às idades $(\underline{\mathrm{F}}(1,98)=13,44 ; \mathrm{p}<0,05)$. Uma ANOVA demonstrou que as crianças mais velhas (8/9 anos; $\underline{\mathrm{n}}=64)$ apresentam maior iniciativa do que as crianças mais novas (6/7 anos; $\underline{\mathrm{n}}=36)$, conforme a Tabela 3.

Tabela 3 - Diferença entre Idades para a Competência Social no THI ( $\underline{n}=100)$

\begin{tabular}{lcccc}
\hline Escalas & $\begin{array}{c}\text { Idades } \\
\text { (em anos) }\end{array}$ & Média & $\underline{\mathrm{dp}}$ & $\underline{\mathrm{F}}(1,98)$ \\
\hline Confiança & $6 / 7$ & 4,13 & 2,04 & 2,45 \\
Auto-Eficácia & $8 / 9$ & 4,84 & 2,21 & 3,20 \\
& $6 / 7$ & 6,27 & 1,87 & $13,44^{*}$ \\
Iniciativa & $8 / 9$ & 6,96 & 1,84 & \multirow{2}{*}{$11,31^{*}$} \\
& $6 / 7$ & 5,13 & 1,80 & \\
Competência Total & $8 / 9$ & 6,45 & 1,67 & \\
& $6 / 7$ & 15,55 & 4,02 & 3,76 \\
\hline
\end{tabular}

$* \mathrm{p}<0,05$

Conforme observado na Tabela 3, há uma temdência para o aumento da competência social na medida em que aumenta a idade em todas as escalas, entretanto, somente nas escalas de iniciativa $(\underline{\mathrm{F}}(1,98)=13,44 ; \mathrm{p}<0,05)$ e competência total $(\underline{\mathrm{F}}(1,98)=11,31 ; \underline{\mathrm{p}}<0,05)$ essa diferença revelou-se significativa. Esse fato demonstra 
que as crianças mais velhas tendem a ser mais competentes socialmente do que as crianças mais jovens.

A análise de fidedignidade do THI alcançou um coeficiente de alpha de Cronbach de 0,50. Esse índice é inferior ao encontrado por Mondell e Tyler (1981; $\underline{r}=0,98)$, sendo considerado baixo pela literatura. Contudo, acredita-se que esse resultado possa estar relacionado ao número reduzido de itens em cada subescala (cinco).

Confrontando os achados deste estudo com os dados obtidos por Mondell e Tyler (1981), observam-se algumas diferenças significativas entre as médias deste grupo e as médias do grupo estudado pelos autores. Para a comparação das médias entre as duas amostras, foram utilizadas somente as médias do grupo de crianças escolares (G1) estudado por Mondell e Tyler, visto que a amostra deste estudo é composta somente por crianças escolares. Ao utilizar o teste $\underline{\mathrm{t}} \mathrm{de}$ Student para uma média populacional, observa-se que as médias das subescalas de auto-eficácia e iniciativa das crianças deste estudo são diferentes estatisticamente das médias encontradas pelos autores (auto-eficácia: $\underline{\mathrm{m}}=6,17$; $\underline{\mathrm{d} p}=2,17$; iniciativa: $\underline{\mathrm{m}}=7,04 ; \underline{\mathrm{d}}=2,08)$. A média de auto-eficácia deste grupo é superior a do estudo de Mondell e Tyler, e a média de iniciativa é inferior a deles (ver Tabela 1). Na subescala de confiança e no escore de competência total, contudo, as médias não são estatisticamente diferentes. Esses dados sugerem que a variável risco - condição que distingue as duas amostras - presente neste estudo possa estar influenciando na determinação dos resultados.

Em seu estudo, Mondell e Tyler (1981) observaram que a baixa pontuação na subescala de iniciativa estava presente nos grupos menos competentes, em contrapartida, alta pontuação nas subescalas de confiança e auto-eficácia estava presente nos grupos mais competentes. Os grupos mais competentes demonstravam mais sentimentos de controle pessoal e responsabilidade sobre os eventos de suas vidas, ao passo que os grupos menos competentes demonstravam mais passividade ao enfrentar as situações adversas. Esse fato era o que basicamente distinguia os dois grupos. A diferença significativa entre as médias da subescala de iniciativa neste estudo e no estudo de Mondell e Tyler indica que as limitações impostas pelo contexto socioeconômicocultural no qual está inserida a amostra deste estudo está interferindo na capacidade destas crianças para interagir com os eventos de vida, prejudicando o desenvolvimento de estratégias para ação. A ausência de oportunidades no ambiente não impede, contudo, que as crianças deste estudo desenvolvam um sentimento de controle pessoal sobre os eventos de suas vidas. A alta pontuação na subescala de auto-eficácia demonstra que essas crianças acreditam nos seus esforços pessoais, fato que contribui para a competência social. Os escores de competência total nesta amostra $(\underline{m}=17,29 ; \mathrm{d} p=4,06)$ e na amostra de crianças escolares estudada por Mondell e Tyler $(\underline{\mathrm{m}}=17,75 ; \underline{\mathrm{d} p}=4,20)$ não são estatistica-mente diferentes (ver Tabela 1), o que sugere que o risco existente no ambiente interfere na capacidade para iniciativa, no entanto, não impede que as crianças possam adaptar-se a ele, demonstrando competência social.

Diferença significativa entre os sexos para a competência social foi observada nessa amostra. Neste estudo, as meninas obtiveram melhores resultados do que os meninos nas subescalas de confiança, autoeficácia e competência total, sendo mais competentes socialmente (ver Tabela 2). Esse achado não corrobora aos resultados encontrados por Mondell e Tyler (1981), apesar de que esses autores observaram que as meninas pontuaram consistentemente mais alto do que os meninos. LaFerniere e Dumas (1996) também verificaram diferença significativa entre os sexos para a competência social em seu estudo, no qual as meninas obtiveram resultados superiores aos dos meninos, demonstrando ser mais competentes socialmente e apresentando menos problemas de comportamento do que eles. Essa diferença sugere que a variável sexo esteja associada com a capacidade para adaptação em situações de estresse. De acordo com LaFreniere e Dumas (1996), é provável que algumas crianças respondam a situações estressantes manifestando comportamentos disruptivos, e existem evidências na literatura de que esse tipo de comportamento é mais freqüente em meninos (ZahnWaxler, Cole \& Barrett, 1991).

Diferença significativa entre grupos etários também foi observada nesta amostra. Os resultados apontam para uma diferença significativa entre as idades, tendo as crianças mais velhas (8/9 anos) obtido um melhor desempenho do que as crianças mais novas (6/7 anos) nas escalas de iniciativa e competência total (ver Tabela 3). Da mesma forma, o estudo de Mondell e Tyler (1981) verificou tal diferença significativa, com as crianças mais velhas ( $9 / 10$ anos) obtendo melhores resultados do que as mais novas (7/8 anos). Kliewer (1991) refere que a diferença entre grupos etários para a competência social é esperada porque crianças mais jovens possuem menos estratégias em seu repertório para lidar com situações adversas do que adolescentes e adultos, pois ainda estão desenvolvendo suas habilidades cognitivas e sua experiência é limitada, comparada às de uma criança mais madura.

\section{Considerações finais}

De uma maneira geral, o THI demonstrou ser um instrumento eficiente para avaliar a competência social em crianças em situação de risco. A adaptação do 
teste à realidade brasileira e, principalmente, ao contexto socioeconômico-cultural da população estudada, facilitou a compreensão das histórias pelas crianças, bem como o levantamento dos resultados. A utilização das ilustrações como um recurso para facilitar a verbalização das crianças contribuiu para que o instrumento se tornasse ainda mais lúdico, favorecendo a diminuição da ansiedade gerada pela situação de testagem, produzindo, assim, respostas mais fidedignas.

Da mesma forma, a adaptação do Manual de Pontuação exigiu da equipe investigadora um esforço para analisar as respostas tendo em vista as limitações impostas pelo contexto no qual as crianças estão inseridas. Nesse sentido, foram valorizadas as respostas que incluíam os recursos disponibilizados pelas crianças, como, no caso da história da subescala de iniciativa relatada neste artigo, presentear o irmão com um desenho feito na escola, ou, ainda, fazer um bolo de chocolate para oferecer ao irmão. Desse modo, a falta de dinheiro não impediu que as crianças encontrassem soluções para os problemas apresentados, tornando-as tão competentes quanto as crianças de outras camadas sociais.

O estudo desenvolvido até o presente permite considerar que características como confiança, autoeficácia e iniciativa podem ser analisadas como atributos de competência social. A importância da identificação dessas características reside na possibilidade de planejamento de programas de intervenção, nos quais podem haver atividades que viabilizem o desenvolvimento dessas características, contribuindo para a competência social. Nesse sentido, o THI consiste em um importante instrumento, que pode ser utilizado como recurso de avaliação para subsidiar tais programas. Os dados obtidos com o THI podem, também, servir para embasar aconselhamento terapêutico, psicopedagógico, educacional ou clínico. Não devem, no entanto, ser utilizados isoladamente para fins de avaliação psicodiagnóstica, quando uma análise mais profunda e criteriosa se faz necessária. É importante ressaltar que psicólogos e outros profissionais que utilizem o THI no seu trabalho devem assumir um compromisso ético, garantindo a proteção aos direitos dos seus participantes.

\section{Referências}

Cecconello, A. M. (1999). Competência social, empatia e representação mental da relação de apego em famílias em situação de risco (Dissertação de Mestrado). Porto Alegre, RS: Universidade Federal do Rio Grande do Sul Pós-Graduação em Psicologia do Desenvolvimento.

Coddington, R. D. (1972). The significance of life events as etiologic factors in the diseases of children
- II: A study of normal population. Journal of Psychosomatic Research, 16, 205-213.

Conrad, M. \& Hammen, C. (1993). Protective and resource factors in high and low-risk children: A comparison of children with unipolar, bipolar, medically ill, and normal mothers. Development and Psychopathology, 5, 593-607.

Elder Jr., G. H. (1998). The life course as a developmental theory. Child Development, 69, 1-12.

Garmezy, N. \& Masten, A. (1994). Chonic Adversities. Em M. Rutter, E. Taylor, \& L. Herson (Orgs.). Child and Adolescent Psychiatry (pp. 191-207). Oxford: Blackwell Scientific.

Garmezy, N., Masten, A. \& Tellegen, A. (1984). The study of stress and competence in children: a building block for developmental psychopathology. Child Development, 55, 97-111.

Kliewer, W. (1991). Coping in middle childhood: relations to competence, type A behavior, monitoring, blunting, and locus of control. Developmental Psychology, 27, 689-697.

LaFreniere, P. J. \& Dumas, J. E. (1996). Social competence and behavior evaluation in children ages 3 to 6 years: the short form (SCBE-30). Psychological Assessment, 8, 369-377.

Luthar, S. S. \& Zigler, E. (1991). Vulnerability and competence: a review of research on resilience in childhood. American Journal Orthopsychiatry, 61, 6-22.

Marques, A. L., Martins, C. B., Krum, F. M. B., Raymundo, M. B., Hoppe, M. W. \& Koller, S. H. (1997). Adaptação do Teste das Histórias Incompletas THI. Trabalho apresentado no VII Encontro Nacional de Testes Psicológicos e I Congresso Ibero-Americano de Avaliação Psicológica, Porto Alegre, RS.

Masten, A. S. (2001). Ordinary magic: resilience processes in development. American Psychologist, 56, 227-238.

Masten, A. S. \& Coatsworth, J. D. (1995). Competence, resilience and psychopatology. Em D. Cicchetti \& D. Cohen (Orgs.). Developmental psychopathology: Vol. 2. Risk, disorder and adaptation (pp. 715-752). New York: Wiley.

Masten, A. \& Garmezy, N. (1985). Risk, vulnerability and protective factors in Developmental Psychopathology. Em B. B. Lahey \& A. E. Kazdin (Orgs.). Advances in Clinical Child Psychology (pp. 1-52). New York: Plenum.

Mondell, S. \& Tyler, F. B. (1981). Child psychosocial competence and its measurement. Journal of Pediatric Psychology, 6, 145-154. 
Rutter, M. (1985). Resilience in the face of adversity: protective factors and resistance to psychiatric disorder. British Journal of Psychiatry, 147, 598-611.

Rutter, M. (1987). Psychosocial resilience and protective mechanisms. American Journal Orthopsychiatry, 57, 316-331.

Rutter, M. (1993). Resilience: some conceptual considerations. Journal of Adolescent Health, 14, 626-631.

Rutter, M. (1996). Psychosocial resilience and protective mechanisms. Em J. Rolf, A. S. Masten, D. Cicchetti, K. H. Nuechterlein \& S. Weintraub (Orgs.). Risk and protective factors in the development of psychopathology (pp. 181-214). New York, NY: Cambridge University Press.

Tyler, F. (1984). El comportamiento psicosocial, la competencia psicosocial individual y las redes de intercambio de recursos como ejemplos de psicologia comunitaria. Revista Latino-Americana de Psicologia, 16, 77-92.

Waters, E. \& Sroufe, L. A. (1983). Social competence as a developmental construct. Developmental Review, 3, 79-97.
Werner, E. E. \& Smith, R. S. (1982). Vulnerable but invinceble: a longitudinal study of resilient cbildren and youth. New York: McGraw Hill.

Werner, E. E. \& Smith, R. S. (1992). Overcoming the odds: bigh risk children from birth to adulthood. London: Cornell University.

Zahn-Waxler, C., Cole, P. M. \& Barrett, K. C. (1991). Guilt and empathy: sex differences and implications for the development of depression. Em J. Garber \& K. A. Dodge (Orgs.). The development of emotion regulation and dysregulation (pp. 243-272). Cambridge: Cambridge University Press.

Zigler, E. \& Trickett, P. K. (1978). IQ, social competence, and evaluation of early childhood intervention programs. American Psychologist, 33, 789-798.

Enviado em março de 2003

Reformulado em maio de 2003

Aprovado em junbo de 2003

Sobre as autoras:

Alessandra Marques Cecconello é psicóloga, mestre e doutora em Psicologia do Desenvolvimento pela Universidade Federal do Rio Grande do Sul, professora da Faculdade Cenecista de Ciências e Letras de Osório (FACOS) e membro do Centro de Estudos Psicológicos sobre Meninos e Meninas de Rua (UFRGS).

Sílvia Helena Koller é psicóloga, doutora em educação (PUC/RS), pesquisadora do CNPq e professora do Curso de Pós-Graduação em Psicologia do Desenvolvimento da Universidade Federal do Rio Grande do Sul. Coordena o Centro de Estudos Psicológicos sobre Meninos e Meninas de Rua (UFRGS). 
